\title{
Author Correction: PV plasticity sustained through D1/5 dopamine signaling required for long-term memory consolidation
}

Smitha Karunakaran, Ananya Chowdhury, Flavio Donato, Charles Quairiaux, Christoph M Michel and Pico Caroni

Correction to: Nature Neuroscience https://doi.org/10.1038/nn.4231, published online 25 January 2016.

In the version of this article initially published, the right panel in Fig. $2 \mathrm{~b}$ was duplicated from the corresponding panel in Fig. $2 \mathrm{c}$, and some data points in Fig. $3 \mathrm{~b}$ were duplicated from Fig. 3a. None of the conclusions in the paper are affected. The errors have been corrected in the HTML and PDF versions of the article, and source data have been posted for the revised panels.
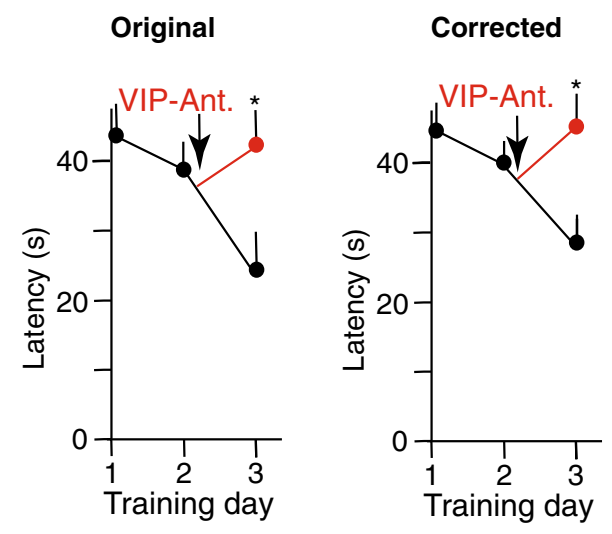

Fig. 2b | Original and corrected.

Original

b

Low-PV plasticity regulation in naive mice
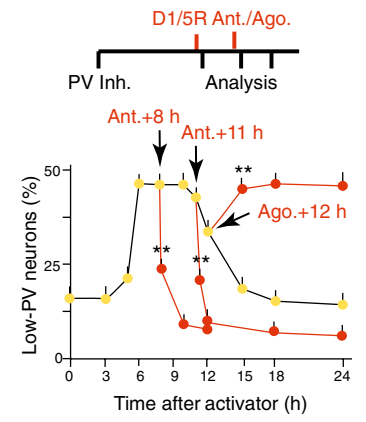

Fig. 3b | Original and corrected.
Corrected

Low-PV plasticity regulation in naive mice
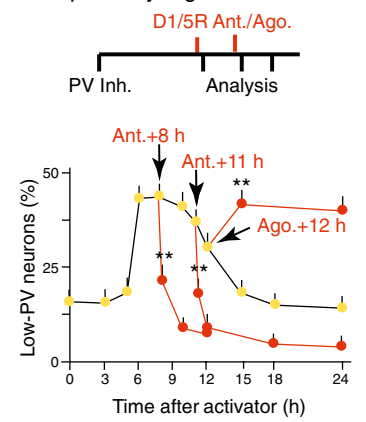

Published online: 16 July 2018

https://doi.org/10.1038/s41593-018-0179-0 